\title{
Serial Change in Serum Chloride During Hospitalization Could Predict Heart Failure Death in Acute Decompensated Heart Failure Patients
}

\author{
Takumi Kondo, MD; Takahisa Yamada, MD, PhD; Shunsuke Tamaki, MD, PhD; \\ Takashi Morita, MD, PhD; Yoshio Furukawa, MD, PhD; Yusuke Iwasaki, MD; \\ Masato Kawasaki, MD; Atsushi Kikuchi, MD; Tatsuhisa Ozaki, MD; Yoshihiro Sato, MD; \\ Masahiro Seo, MD; Iyo Ikeda, MD; Eiji Fukuhara, MD; Makoto Abe, MD; \\ Jun Nakamura, MD; Yasushi Sakata, MD, PhD; Masatake Fukunami, MD, PhD
}

\begin{abstract}
Background: Although hyponatremia predicts morbidity and mortality in acute decompensated heart failure (ADHF), hypochloremia is also independently associated with poor prognosis in ADHF. Little is known, however, about the prognostic value of serial change in serum chloride during hospitalization in ADHF patients.
\end{abstract}

Methods and Results: We prospectively studied 208 ADHF survivors after discharge and divided them into 4 groups according to serum chloride on admission and at discharge: (1) persistent hypochloremia group $(n=12)$, hypochloremia both on admission and at discharge; (2) progressive hypochloremia group ( $n=42)$, development of hypochloremia after admission; (3) improved hypochloremia group ( $n=14)$, hypochloremia only on admission; and (4) no hypochloremia group, no hypochloremia during hospitalization ( $n=140)$. During a mean follow-up period of $1.86 \pm 0.76$ years, 20 of 208 patients had heart failure death (HFD). In a model adjusted for hyponatremia, hypochloremia both on admission and at discharge was still significantly associated with HFD. Hyponatremia, however, was not significantly associated with HFD after adjustment for hypochloremia. Patients with persistent hypochloremia (HR, 9.13; 95\% $\mathrm{Cl}$ : 2.56-32.55) and with progressive hypochloremia (HR, 4.65; 95\% Cl: 1.61-13.4) had a significantly greater risk of HFD than those without hypochloremia during hospitalization.

Conclusions: Both persistent hypochloremia and progressive hypochloremia during hospitalization are associated with HFD in ADHF patients.

Key Words: Acute decompensated heart failure; Heart failure death; Hypochloremia; Serial change; Serum chloride

$\mathbf{E}$ lectrolyte abnormalities often accompany heart failure (HF) because of the activated neurohormone systems such as the renin-angiotensin-aldosterone system (RAAS) and arginine vasopressin system, and because of decongestive therapy with loop and thiazide diuretics. ${ }^{1}$ Hyponatremia has prognostic value in both acute decompensated HF (ADHF) and chronic HF failure patients. ${ }^{26}$ In theory, however, serum sodium does not decrease by itself and an anion such as serum chloride and bicarbonate should be lowered in parallel with serum sodium to maintain electroneutrality. Recently hypochloremia was found to have strong prognostic value in patients with ADHF and chronic HF, independent of hyponatremia. ${ }^{7-10}$ Chloride has an important role in acid-base homeostasis, plasma electroneutrality and the activation of neumohor- mone systems such as the RAAS. ${ }^{11}$ Furthermore, chloride regulates the sodium-potassium-chloride cotransporter and sodium-chloride cotransporter in the kidney, and, consequently, renal salt reabsorption..$^{12,13}$ The impact, however, of serial change in serum chloride during hospitalization on mortality and morbidity in ADHF patients has not been well described. In the present study, the aim was to evaluate the prognostic power of serial change in serum chloride during hospitalization in ADHF patients.

\section{Methods}

We prospectively enrolled 293 consecutive patients with ADHF and emergency hospital admission, and who were discharged with survival between October 2011 and

Received September 3, 2017; revised manuscript received December 31, 2017; accepted January 17, 2018; released online February 22, 2018 Time for primary review: 26 days

Division of Cardiology, Osaka General Medical Center, Osaka (T.K., T.Y., S.T., T.M., Y.F., Y.I., M.K., A.K., T.O., Y. Sato, M.S., I.I., E.F., M.A., J.N., M.F.); Division of Cardiovascular Medicine, Osaka University Graduate School of Medicine, Suita (T.K., Y. Sakata), Japan

Mailing address: Takumi Kondo, MD, Division of Cardiovascular Medicine, Osaka University Graduate School of Medicine, 2-2 Yamadaoka, Suita 565-0871, Japan. E-mail: takumikondou2000@yahoo.co.jp

ISSN-1346-9843 All rights are reserved to the Japanese Circulation Society. For permissions, please e-mail: cj@j-circ.or.jp 
February 2014 in the present study, which is titled "Osaka Prefectural trial: Acute heart failure syndrome Registry (OPAR: UMIN 000015246)". ADHF was diagnosed on clinical signs and symptoms according to the Framingham Heart Study criteria. These criteria require the presence of at least 2 major criteria or 1 major criterion in addition to 2 minor criteria to confirm HF.14 Patients were excluded from this study if serum chloride was not measured at discharge $(n=8)$; if they had severe valvular disease or coronary artery disease needing urgent operation during hospitalization $(n=3)$; if they withdrew informed consent $(n=2)$; if they did not have long-term prognosis because of terminal stage cancer $(n=1)$; or if they were judged as inappropriate as subjects for this clinical study by primary physicians $(n=6)$. Patients who had already been enrolled in the registry were also excluded if they were re-hospitalized for worsening $\mathrm{HF}(\mathrm{n}=65)$. After excluding these patients, 208 ADHF patients (mean age, $74 \pm 13$ years; 116 men, 92 women) were analyzed in the present study. ADHF was due to hypertensive heart disease in 60 patients, idiopathic dilated cardiomyopathy in 54 patients, ischemic heart disease in 50 patients, valvular heart disease in 23 patients, tachycardia-induced cardiomyopathy in 10 patients, hypertrophic cardiomyopathy in 5 patients, restrictive cardiomyopathy in 1 patient, cardiac amyloidosis in 1 patient, congenital heart disease in 1 patient, takotsubo

\begin{tabular}{|c|c|c|c|c|c|c|}
\hline & $\begin{array}{c}\text { Persistent } \\
\text { hypochloremia }\end{array}$ & $\begin{array}{c}\text { Progressive } \\
\text { hypochloremia }\end{array}$ & $\begin{array}{c}\text { Improved } \\
\text { hypochloremia }\end{array}$ & $\begin{array}{c}\text { No } \\
\text { hypochloremia }\end{array}$ & 4 groups & $\begin{array}{l}\text { Progressive } \\
\text { vs. No } \\
\text { hypochloremia }\end{array}$ \\
\hline & & & & & P-value & P-value \\
\hline $\mathrm{n}$ & 12 & 42 & 14 & 140 & & \\
\hline Age (years) & $76(70-85)$ & 79 (70-84) & $68(62-78)$ & $77(66-83)$ & 0.288 & 0.218 \\
\hline Gender (male) & 42 & 52 & 64 & 57 & 0.643 & 0.600 \\
\hline Ischemic origin & 8 & 24 & 29 & 22 & 0.632 & 0.835 \\
\hline Prior HF hospitalization & 67 & 33 & 21 & 21 & 0.005 & 0.149 \\
\hline Atrial fibrillation & 75 & 61 & 36 & 45 & 0.059 & 0.078 \\
\hline Hypertension & 67 & 79 & 71 & 84 & 0.309 & 0.482 \\
\hline Diabetes mellitus & 58 & 40 & 57 & 46 & 0.584 & 0.598 \\
\hline Dyslipidemia & 42 & 45 & 29 & 54 & 0.231 & 0.379 \\
\hline Length of stay (days) & $22(17-35)$ & $23(17-29)$ & $19(18-24)$ & $21(18-26)$ & 0.928 & 0.665 \\
\hline \multicolumn{7}{|l|}{ Assessment on admission } \\
\hline NYHA class III/IV & $2 / 10$ & $6 / 36$ & $2 / 12$ & $19 / 121$ & 0.963 & 1.000 \\
\hline $\begin{array}{l}\text { Nohria-Stevenson } \\
\text { classification on } \\
\text { admission }\end{array}$ & & & & & 0.663 & 0.447 \\
\hline Wet/warm & 58 & 64 & 79 & 72 & & \\
\hline Dry/cold & 0 & 0 & 0 & 2 & & \\
\hline Wet/cold & 42 & 36 & 21 & 26 & & \\
\hline $\mathrm{SBP}(\mathrm{mmHg})$ & $115(99-157)$ & $144(129-158)$ & $139(115-175)$ & $159(138-184)$ & 0.002 & 0.003 \\
\hline Heart rate (beats/min) & 87 (68-91) & $101(84-121)$ & 89 (85-92) & $103(84-124)$ & 0.033 & 0.709 \\
\hline Body weight (kg) & $51(45-67)$ & $51(46-60)$ & $54(53-60)$ & $58(50-69)$ & 0.118 & 0.021 \\
\hline LVEDd (mm) & $52 \pm 13$ & $51 \pm 10$ & $53 \pm 10$ & $54 \pm 10$ & 0.286 & 0.115 \\
\hline LVEF & $48(32-58)$ & $45(33-60)$ & $46(41-54)$ & $47(37-59)$ & 0.929 & 0.674 \\
\hline LAD (mm) & $46(39-52)$ & $42(37-49)$ & $44(41-48)$ & $42(38-47)$ & 0.547 & 0.800 \\
\hline Assisted ventilation & 42 & 24 & 43 & 36 & 0.364 & 0.141 \\
\hline \multicolumn{7}{|l|}{$\begin{array}{l}\text { Medications during } \\
\text { hospitalization }\end{array}$} \\
\hline Inotropic agents & 25 & 7 & 14 & 12 & 0.338 & 0.574 \\
\hline Nitrovasodilators & 50 & 71 & 71 & 82 & 0.041 & 0.133 \\
\hline Carperitide & 33 & 48 & 14 & 39 & 0.162 & 0.371 \\
\hline $\begin{array}{l}\text { Loop diuretics } \\
\text { (furosemide/azosemide) }\end{array}$ & $100 / 0$ & $88 / 12$ & $100 / 0$ & $97 / 3$ & 0.129 & 0.039 \\
\hline Loop diuretics dose $(\mathrm{mg})$ & 595 (409-862) & $453(326-752)$ & 380 (42-679) & $344(229-518)$ & 0.013 & 0.005 \\
\hline Thiazides & 58 & 36 & 29 & 7 & $<0.001$ & $<0.001$ \\
\hline Tolvaptan & 8 & 0 & 0 & 3 & 0.294 & 0.575 \\
\hline \multicolumn{7}{|l|}{ Assessment at discharge } \\
\hline NYHA class I/II/III/IV & $1 / 3 / 8 / 0$ & $10 / 18 / 14 / 0$ & $5 / 3 / 6 / 0$ & $57 / 44 / 39 / 0$ & 0.046 & 0.129 \\
\hline $\mathrm{SBP}(\mathrm{mmHg})$ & $105(96-117)$ & $111(106-121)$ & $124(115-129)$ & $115(105-130)$ & 0.135 & 0.214 \\
\hline Heart rate (beats/min) & $70(60-76)$ & $65(58-72)$ & $63(60-68)$ & $65(58-73)$ & 0.559 & 0.957 \\
\hline Body weight $(\mathrm{kg})$ & $49(32-63)$ & $45(41-55)$ & $50(47-52)$ & $52(43-61)$ & 0.071 & 0.012 \\
\hline
\end{tabular}

(Table 1 continued the next page.) 


\begin{tabular}{|c|c|c|c|c|c|c|}
\hline & \multirow[t]{2}{*}{$\begin{array}{c}\text { Persistent } \\
\text { hypochloremia }\end{array}$} & \multirow[t]{2}{*}{$\begin{array}{c}\text { Progressive } \\
\text { hypochloremia }\end{array}$} & \multirow[t]{2}{*}{$\begin{array}{c}\text { Improved } \\
\text { hypochloremia }\end{array}$} & \multirow[t]{2}{*}{$\begin{array}{c}\text { No } \\
\text { hypochloremia }\end{array}$} & \multirow{2}{*}{$\begin{array}{c}4 \text { groups } \\
\text { P-value }\end{array}$} & \multirow{2}{*}{$\begin{array}{c}\begin{array}{c}\text { Progressive } \\
\text { vs. No } \\
\text { hypochloremia }\end{array} \\
\text { P-value }\end{array}$} \\
\hline & & & & & & \\
\hline \multicolumn{7}{|l|}{ Medications at discharge } \\
\hline ACEI & 33 & 21 & 29 & 29 & 0.758 & 0.431 \\
\hline ARB & 8 & 14 & 43 & 34 & 0.017 & 0.016 \\
\hline$\beta$-blocker & 92 & 86 & 79 & 91 & 0.392 & 0.375 \\
\hline Spironolactone & 58 & 50 & 43 & 36 & 0.212 & 0.107 \\
\hline Diuretics & 83 & 95 & 57 & 84 & 0.009 & 0.072 \\
\hline Loop diuretics & 83 & 95 & 57 & 83 & 0.010 & 0.046 \\
\hline Furosemide/azosemide & $92 / 8$ & $86 / 14$ & $86 / 14$ & $91 / 9$ & 0.540 & 0.540 \\
\hline $\begin{array}{l}\text { Loop diuretics dose } \\
\text { (mg/day) }\end{array}$ & $40(20-60)$ & $40(20-40)$ & $20(0-40)$ & $20(20-40)$ & 0.005 & 0.002 \\
\hline Thiazides & 42 & 26 & 0 & 6 & $<0.001$ & $<0.001$ \\
\hline Tolvaptan & 0 & 0 & 0 & 1 & 1.000 & 1.000 \\
\hline \multicolumn{7}{|l|}{ Laboratory data on admission } \\
\hline Sodium (mmol/L) & $135(133-136)$ & $138(136-141)$ & $133(130-137)$ & $140(137-141)$ & $<0.001$ & 0.282 \\
\hline Potassium (mmol/L) & $4.4(3.6-4.8)$ & $4.3(3.7-4.7)$ & $4.2(3.8-4.3)$ & $4.1(3.7-4.5)$ & 0.718 & 0.341 \\
\hline Chloride (mmol/L) & $93(92-94)$ & $103(99-105)$ & $96(94-97)$ & $104(102-106)$ & $<0.001$ & 0.020 \\
\hline Hemoglobin (g/dL) & $11.5 \pm 1.7$ & $11.3 \pm 2.4$ & $12.3 \pm 2.7$ & $11.9 \pm 2.5$ & 0.395 & 0.184 \\
\hline Creatinine (mg/dL) & $\begin{array}{c}1.88 \\
(1.49-2.41)\end{array}$ & $\begin{array}{c}1.20 \\
(0.74-1.59)\end{array}$ & $\begin{array}{c}1.24 \\
(0.95-4.46)\end{array}$ & $\begin{array}{c}1.16 \\
(0.83-1.71)\end{array}$ & 0.032 & 0.450 \\
\hline eGFR $\left(\mathrm{mL} / \mathrm{min} / 1.73 \mathrm{~m}^{2}\right)$ & $23(18-32)$ & $41(26-66)$ & $44(12-55)$ & $43(27-60)$ & 0.018 & 0.457 \\
\hline BUN $(\mathrm{mg} / \mathrm{dL})$ & $57(24-62)$ & $27(18-41)$ & $25(17-35)$ & $24(17-33)$ & 0.072 & 0.345 \\
\hline Uric acid (mg/dL) & $7.3(5.8-7.5)$ & $7.1(6.2-10.1)$ & $5.0(3.7-7.5)$ & $6.9(5.5-8.8)$ & 0.259 & 0.292 \\
\hline Albumin (mg/dL) & $3.5(3.1-3.8)$ & $3.5(3.2-3.7)$ & $3.6(3.3-3.8)$ & $3.5(3.2-3.8)$ & 0.749 & 0.353 \\
\hline $\mathrm{BNP}(\mathrm{pg} / \mathrm{mL})$ & $\begin{array}{c}519 \\
(210-1,193)\end{array}$ & $\begin{array}{c}1,000 \\
(410-1,847)\end{array}$ & $\begin{array}{c}1,190 \\
(667-1,888)\end{array}$ & $\begin{array}{c}851 \\
(492-1,582)\end{array}$ & 0.464 & 0.940 \\
\hline \multicolumn{7}{|l|}{ Laboratory data at discharge } \\
\hline Sodium (mmol/L) & $133(132-134)$ & $137(133-139)$ & $139(135-140)$ & $139(137-141)$ & $<0.001$ & $<0.001$ \\
\hline Potassium (mmol/L) & $4.5(4.1-4.8)$ & $4.1(3.8-4.6)$ & $4.3(3.8-4.7)$ & $4.2(3.9-4.5)$ & 0.499 & 0.529 \\
\hline Chloride (mmol/L) & $94(93-96)$ & $95(92-97)$ & $101(99-102)$ & $102(100-104)$ & $<0.001$ & $<0.001$ \\
\hline Hemoglobin (g/dL) & $11.3 \pm 1.7$ & $11.7 \pm 2.3$ & $11.0 \pm 1.6$ & $11.7 \pm 2.4$ & 0.917 & 0.930 \\
\hline Creatinine (mg/dL) & $\begin{array}{c}2.10 \\
(1.49-2.57)\end{array}$ & $\begin{array}{c}1.16 \\
(0.76-1.74)\end{array}$ & $\begin{array}{c}1.13 \\
(0.93-2.24)\end{array}$ & $\begin{array}{c}1.13 \\
(0.87-1.63)\end{array}$ & 0.036 & 0.554 \\
\hline eGFR $\left(\mathrm{mL} / \mathrm{min} / 1.73 \mathrm{~m}^{2}\right)$ & $24(17-29)$ & $44(24-65)$ & $46(22-61)$ & $46(30-58)$ & 0.012 & 0.665 \\
\hline BUN $(\mathrm{mg} / \mathrm{dL})$ & $47(33-67)$ & $27(19-44)$ & $19(17-26)$ & $25(18-34)$ & $<0.001$ & 0.326 \\
\hline Uric acid (mg/dL) & $7.5(5.4-9.2)$ & $7.3(5.4-9.0)$ & $5.7(4.4-6.9)$ & $6.8(6.0-8.3)$ & 0.0504 & 0.902 \\
\hline Albumin (mg/dL) & $3.4(2.9-3.8)$ & $3.4(3.1-3.6)$ & $3.4(3.2-3.5)$ & $3.4(3.0-3.7)$ & 0.988 & 0.927 \\
\hline $\mathrm{BNP}(\mathrm{pg} / \mathrm{mL})$ & $324(140-420)$ & $252(82-393)$ & $352(164-566)$ & $182(101-319)$ & 0.309 & 0.418 \\
\hline
\end{tabular}

Data given as mean \pm SD, or median (IQR) or \%. ACEI, angiotensin-converting enzyme inhibitor; ADHF, acute decompensated heart failure; ARB, angiotensin receptor blocker; BMI, body mass index; BNP, brain natriuretic peptide; BUN, blood urea nitrogen; eGFR, estimated glomerular filtration rate; HF, heart failure; LAD, left atrial dimension; LVEDd, left ventricular end-diastolic dimension; LVEF, left ventricular ejection fraction; NYHA, New York Heart Association; SBP, systolic blood pressure.

cardiomyopathy in 1 patient, cor pulmonale in 1 patient and catecholamine-induced cardiomyopathy in 1 patient. The New York Heart Association (NYHA) functional class was III in 29 patients and IV in 179 patients. Mean left ventricular ejection fraction (LVEF) was $47 \pm 15 \%$. All patients gave written informed consent for participation in this study, which was approved by the Osaka General Medical Center's Review Committee. This study conformed to the ethical guidelines outlined in the Declaration of Helsinki. ${ }^{15}$

For analysis, we assessed total loop diuretic dose during hospitalization, which was converted to furosemide equivalent i.v. dose. We considered $60 \mathrm{mg}$ azosemide to be equivalent to $40 \mathrm{mg}$ oral furosemide. No patient took torasemide in the present study. Half of the oral dose was used to make an adjustment for biological availability. ${ }^{16}$
Additionally, loop diuretic dose on admission and at discharge was described as oral furosemide equivalent dose.

All patients underwent echocardiography and venous blood sampling during hospitalization. On echocardiography, LV end-diastolic dimension (LVEDd), LV end-systolic dimension (LVESd), left atrial (LA) dimension and LVEF were measured by standard techniques. Blood sampling for assessment of complete blood count, serum sodium, potassium, chloride, creatinine, blood urea nitrogen (BUN), uric acid, albumin and brain natriuretic peptide, was drawn from an i.v. cannula after the patients had rested for $>30 \mathrm{~min}$ in the supine position. Estimated glomerular filtration rate (eGFR) was calculated using the modified isotope dilution mass spectrometry traceable modification of diet in renal disease (IDMS-MDRD) study equation with a Japanese coefficient. ${ }^{17}$ 
Patients were divided into 4 groups according to serum chloride level on admission and at discharge: (1) persistent hypochloremia group with hypochloremia both on admission and at discharge; (2) progressive hypochloremia group with the development of hypochloremia after admission; (3) improved hypochloremia group with hypochloremia only on admission but not at discharge; and (4) no hypochloremia group, with no hypochloremia during hospitalization. Hypochloremia was defined as serum chloride $<98 \mathrm{mmol} / \mathrm{L}$, the lower limit of normal range. Hyponatremia was defined as serum sodium $<136 \mathrm{mmol} / \mathrm{L}$, consistent with a previously published definition. ${ }^{18}$

After discharge, all patients were followed up in the present HF unit at least every 1 or 2 months. The primary endpoint of this study was HF death (HFD). HFD was defined as death resulting from a deterioration of congestive HF, with progression of congestive symptoms. We also checked for non-cardiovascular death and all-cause death.

\section{Statistical Analysis}

Student's t-test and one-way analysis of variance were used to compare differences in continuous variables. Normally distributed data are presented as mean $\pm \mathrm{SD}$; non-normally distributed data are presented as median (IQR), and Mann-Whitney test and Kruskal-Wallis rank sum test were used. Fisher's exact test was used to compare differences in categorical variables. Cumulative event rates were calculated using the Kaplan-Meier method. Comparison of event-free survival rates between groups was assessed using 2-sided log-rank test. Cox proportional hazards regression models were used to identify patients at risk of HFD and to calculate the multivariate-adjusted hazard ratios (HR) and 95\% CI. Logistic regression analysis was used to estimate the association of hypochloremia on admission and at discharge with a number of variables and to calculate the multivariate-adjusted odds ratios (OR) and 95\% CI in ADHF patients. All data were analyzed using EZR version 1.03 (Saitama Medical Center, Jichi Medical

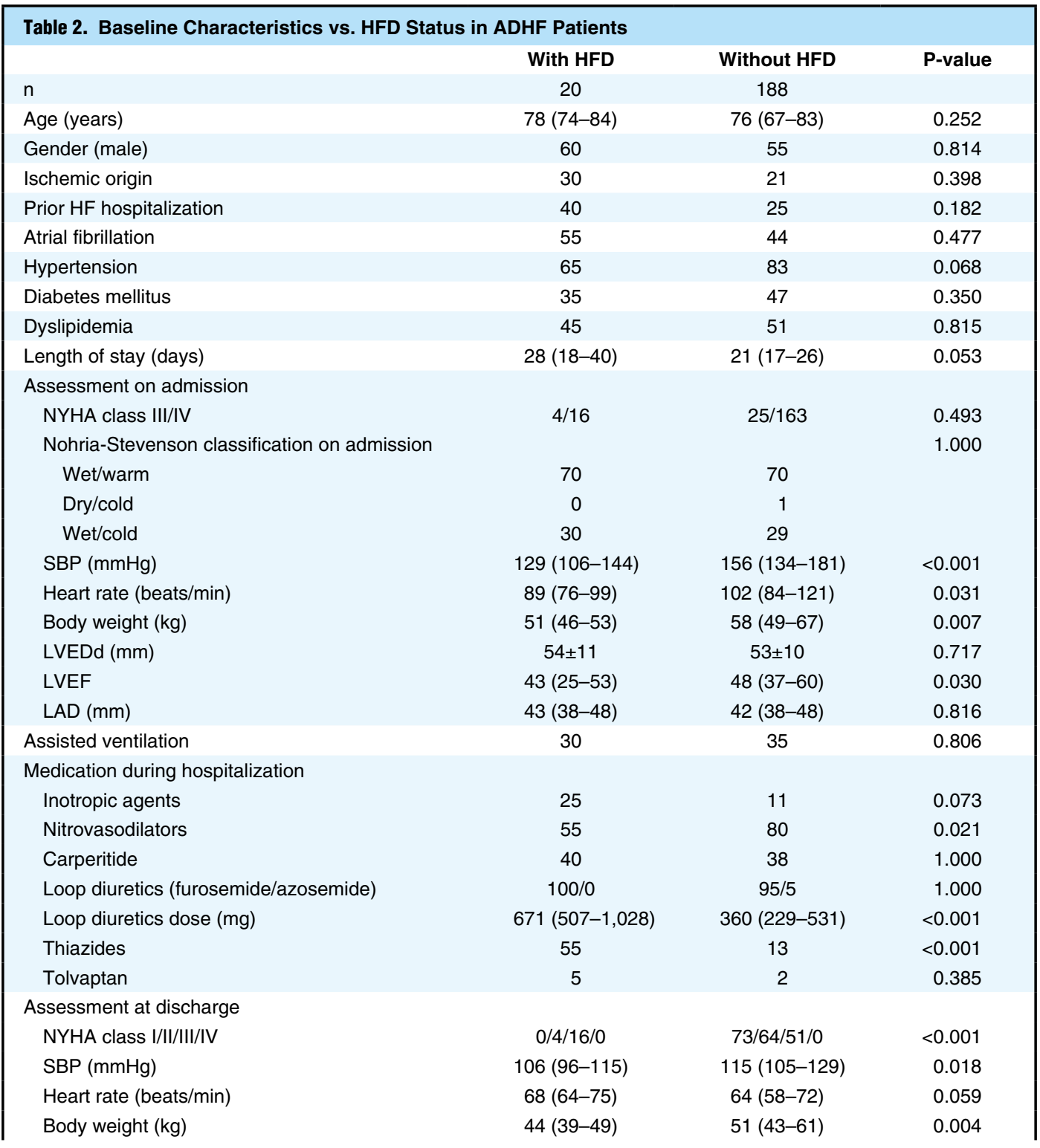

(Table 2 continued the next page.) 


\begin{tabular}{|c|c|c|c|}
\hline & With HFD & Without HFD & P-value \\
\hline \multicolumn{4}{|l|}{ Medications at discharge } \\
\hline ACEI & 15 & 29 & 0.291 \\
\hline ARB & 20 & 30 & 0.444 \\
\hline$\beta$-blocker & 85 & 90 & 0.451 \\
\hline Spironolactone & 55 & 39 & 0.230 \\
\hline Diuretics & 95 & 83 & 0.211 \\
\hline Loop diuretics & 95 & 82 & 0.209 \\
\hline Furosemide/azosemide & $90 / 10$ & $90 / 10$ & 1.000 \\
\hline Loop diuretics dose (mg/day) & $40(20-40)$ & $20(20-40)$ & 0.018 \\
\hline Thiazides & 40 & 9 & $<0.001$ \\
\hline Tolvaptan & 0 & 1 & 1.000 \\
\hline \multicolumn{4}{|l|}{ Laboratory data on admission } \\
\hline Sodium (mmol/L) & $137(134-138)$ & $139(136-141)$ & 0.007 \\
\hline Potassium (mmol/L) & $4.4(3.8-4.8)$ & $4.1(3.7-4.5)$ & 0.221 \\
\hline Chloride (mmol/L) & $100(97-104)$ & $103(100-106)$ & 0.040 \\
\hline Hemoglobin (g/dL) & $10.3 \pm 1.7$ & $11.9 \pm 2.5$ & 0.005 \\
\hline Creatinine $(\mathrm{mg} / \mathrm{dL})$ & $1.86(1.33-2.48)$ & $1.17(0.81-1.69)$ & 0.014 \\
\hline eGFR $\left(\mathrm{mL} / \mathrm{min} / 1.73 \mathrm{~m}^{2}\right)$ & $25(15-40)$ & $43(27-60)$ & 0.014 \\
\hline $\operatorname{BUN}(\mathrm{mg} / \mathrm{dL})$ & $46(25-59)$ & $24(17-36)$ & $<0.001$ \\
\hline Uric acid (mg/dL) & $8.5(6.6-9.5)$ & $6.8(5.3-8.7)$ & 0.186 \\
\hline Albumin (mg/dL) & $3.4(3.0-3.5)$ & $3.5(3.2-3.8)$ & 0.044 \\
\hline $\operatorname{BNP}(p g / m L)$ & $676(475-1,820)$ & $886(449-1,601)$ & 0.858 \\
\hline \multicolumn{4}{|l|}{ Laboratory data at discharge } \\
\hline Sodium (mmol/L) & $136(133-139)$ & $139(136-141)$ & 0.033 \\
\hline Potassium (mmol/L) & $4.2(3.8-4.5)$ & $4.2(3.9-4.5)$ & 0.856 \\
\hline Chloride $(\mathrm{mmol} / \mathrm{L})$ & $97(92-100)$ & $101(98-103)$ & 0.002 \\
\hline Hemoglobin (g/dL) & $9.8 \pm 1.7$ & $11.8 \pm 2.2$ & $<0.001$ \\
\hline Creatinine $(\mathrm{mg} / \mathrm{dL})$ & $1.58(1.18-2.91)$ & $1.12(0.85-1.67)$ & 0.035 \\
\hline eGFR (mL/min/1.73 m²) & $28(15-43)$ & $46(29-58)$ & 0.034 \\
\hline $\mathrm{BUN}(\mathrm{mg} / \mathrm{dL})$ & $33(26-53)$ & $25(18-37)$ & 0.045 \\
\hline Uric acid (mg/dL) & $7.4(3.9-8.9)$ & $6.8(5.8-8.3)$ & 0.736 \\
\hline Albumin (mg/dL) & $3.1(2.7-3.4)$ & $3.4(3.0-3.7)$ & 0.008 \\
\hline $\mathrm{BNP}(\mathrm{pg} / \mathrm{mL})$ & $302(194-697)$ & $189(99-360)$ & 0.011 \\
\hline
\end{tabular}

Data given as mean $\pm \mathrm{SD}$, median (IQR) or \%. HFD, HF death. Other abbreviations as in Table 1.

University, Saitama, Japan). ${ }^{19} \mathrm{P}<0.05$ was considered statistically significant.

\section{Results}

Of the 208 patients, hypochloremia was seen in 26 on admission and in 54 at discharge, that is, 12 patients in the persistent hypochloremia group, 42 patients in the progressive hypochloremia group, 14 in the improved hypochloremia group and 140 in the no hypochloremia group. Baseline characteristics in the ADHF patients are listed in Table 1. There were no significant differences in baseline characteristics such as age, gender, ischemic origin, atrial fibrillation (AF), hypertension, diabetes mellitus, length of stay, LVEDd, LA dimension or LVEF between these 4 groups, except for prior hospitalization for HF. As for admission parameters, statistically significant differences between the groups were seen with regard to systolic blood pressure (SBP), serum sodium and creatinine, and eGFR. With regard to medication during hospitalization, statistically significant differences between the groups were seen with regard to the use of nitrovasodilators, thiazides, and loop diuretic dose. With regard to discharge parameters, statistically significant differences between the groups were seen with regard to NYHA class, prevalence of angiotensin II receptor blocker (ARB) and diuretics use, serum sodium, creatinine, and BUN, and eGFR. In particular, patients with progressive hypochloremia had significantly lower SBP on admission, lower prevalence of ARB use at discharge, greater loop diuretic dose and prevalence of thiazide use during hospitalization, compared with patients without hypochloremia.

With regard to serum sodium, 43 and 51 of 208 patients had hyponatremia on admission and at discharge, respectively. Hyponatremia was observed in 16 of 26 patients with admission hypochloremia, and in 28 of 54 patients with discharge hypochloremia. Serum chloride and sodium decreased during hospitalization in 137 and in 101 of the 208 patients, respectively. Although both serum chloride and sodium decreased during hospitalization in 80 patients, only serum chloride and only sodium decreased in 57 and in 21 patients, respectively. More patients had a decrease in only serum chloride during hospitalization compared with those with only serum sodium decrease ( $42 \%$ vs. $21 \%$, $\mathrm{P}=0.0001$ ).

During a follow-up period of $1.86 \pm 0.76$ years (range, 0.05-3.39 years). HFD was observed in 20 of 208 ADHF patients, while death from non-cardiovascular cause was 


\begin{tabular}{|c|c|c|}
\hline & \multicolumn{2}{|c|}{ Univariate analysis } \\
\hline & P-value & $\mathrm{HR}(95 \% \mathrm{Cl})$ \\
\hline SBP & 0.001 & $0.974(0.959-0.989)$ \\
\hline Heart rate & 0.017 & $0.977(0.958-0.996)$ \\
\hline LVEF & 0.009 & $0.961(0.933-0.99)$ \\
\hline Nitrovasodilators during hospitalization & 0.018 & $0.346(0.143-0.836)$ \\
\hline Loop diuretics dose during hospitalization & $<0.001$ & $1.001(1.001-1.002)$ \\
\hline NYHA class at discharge & $<0.001$ & $6.813(2.605-17.820)$ \\
\hline ACEI or ARB & 0.022 & $0.326(0.125-0.849)$ \\
\hline Diuretics & 0.210 & $3.619(0.484-27.090)$ \\
\hline \multicolumn{3}{|l|}{ Laboratory data on admission } \\
\hline Sodium & 0.017 & $0.908(0.838-0.983)$ \\
\hline Chloride & 0.035 & $0.916(0.845-0.994)$ \\
\hline Hemoglobin & 0.004 & $0.768(0.642-0.920)$ \\
\hline Creatinine & 0.159 & $1.148(0.947-1.392)$ \\
\hline eGFR & 0.009 & $0.970(0.949-0.992)$ \\
\hline BUN & $<0.001$ & $1.046(1.026-1.068)$ \\
\hline Albumin & 0.021 & $0.404(0.187-0.873)$ \\
\hline \multicolumn{3}{|l|}{ Laboratory data at discharge } \\
\hline Sodium & 0.032 & $0.891(0.802-0.990)$ \\
\hline Chloride & $<0.001$ & $0.863(0.795-0.935)$ \\
\hline eGFR & 0.031 & $0.977(0.956-0.998)$ \\
\hline \multicolumn{3}{|l|}{ Models with hyponatremia on admission } \\
\hline Hypochloremia & 0.012 & $3.484(1.323-9.179)$ \\
\hline Hyponatremia & 0.269 & $1.777(0.641-4.919)$ \\
\hline \multicolumn{3}{|l|}{ Model with hyponatremia at discharge } \\
\hline Hypochloremia & 0.008 & $3.880(1.424-10.570)$ \\
\hline Hyponatremia & 0.457 & $1.453(0.543-3.890)$ \\
\hline \multicolumn{3}{|l|}{ Model with eGFR on admission } \\
\hline Hypochloremia & 0.043 & $2.914(1.035-8.207)$ \\
\hline eGFR & 0.008 & $0.966(0.941-0.991)$ \\
\hline \multicolumn{3}{|l|}{ Model with eGFR at discharge } \\
\hline Hypochloremia & 0.001 & $4.634(1.805-11.900)$ \\
\hline eGFR & 0.035 & $0.975(0.953-0.998)$ \\
\hline \multicolumn{3}{|l|}{ Models with loop diuretics at discharge } \\
\hline Hypochloremia & 0.002 & $4.190(1.693-10.370)$ \\
\hline Diuretics & 0.369 & $2.539(0.333-19.380)$ \\
\hline
\end{tabular}

Abbreviations as in Tables 1,2.

observed in 22 patients (cancer in 6, infection in 11, respiratory insufficiency in 3 , hepatic cirrhosis in 1 and age-related causes in 1 patient). Furthermore, 11 patients had sudden cardiac death and 3 patients had cerebrovascular death. In total, 56 of 208 patients died. Baseline characteristics in ADHF patients according to HFD status are listed in Table 2. Patients with HFD had significantly lower SBP and LVEF, higher NYHA class at discharge, loop diuretics dose and prevalence of thiazide, lower hemoglobin, serum sodium, albumin and eGFR, higher serum creatinine and BUN than those without HFD. With regard to serum chloride, patients with HFD had significantly lower serum chloride both on admission and at discharge than those without HFD. In contrast, there were no significant differences in serum chloride both on admission and at discharge between patients with and without non-cardiovascular death. Furthermore, median serum chloride at discharge was significantly lower in patients with than in those without all-cause death $(99 \mathrm{mmol} / \mathrm{L}$; IQR, $95-103 \mathrm{mmol} / \mathrm{L}$ vs.
$101 \mathrm{mmol} / \mathrm{L}$; IQR, 99-103 mmol/L, P=0.033).

On univariate Cox proportional hazard analysis, serum chloride on admission and at discharge, SBP and heart rate on admission, LVEF, prevalence of nitrovasodilators and loop diuretics dose during hospitalization, NYHA class at discharge, prevalence of angiotensin-converting enzyme inhibitor or ARB, hemoglobin level and serum BUN, albumin and eGFR on admission were significantly associated with HFD, while there were no significant associations between HFD and age, NYHA class on admission, prior hospitalization for worsening $\mathrm{HF}$, presence of $\mathrm{AF}$, body mass index, serum creatinine level or serum uric acid level. In a model adjusted for hyponatremia, both hypochloremia on admission (C-index, 0.592; 95\% CI: 0.516-0.668) and on discharge (C-index, 0.722; 95\% CI: 0.606-0.838) were still significantly associated with HFD (Table 3). Regarding all-cause death, hypochloremia at discharge was also significantly associated with all-cause death after adjustment for hyponatremia (C-index, 0.609; 95\% CI: 


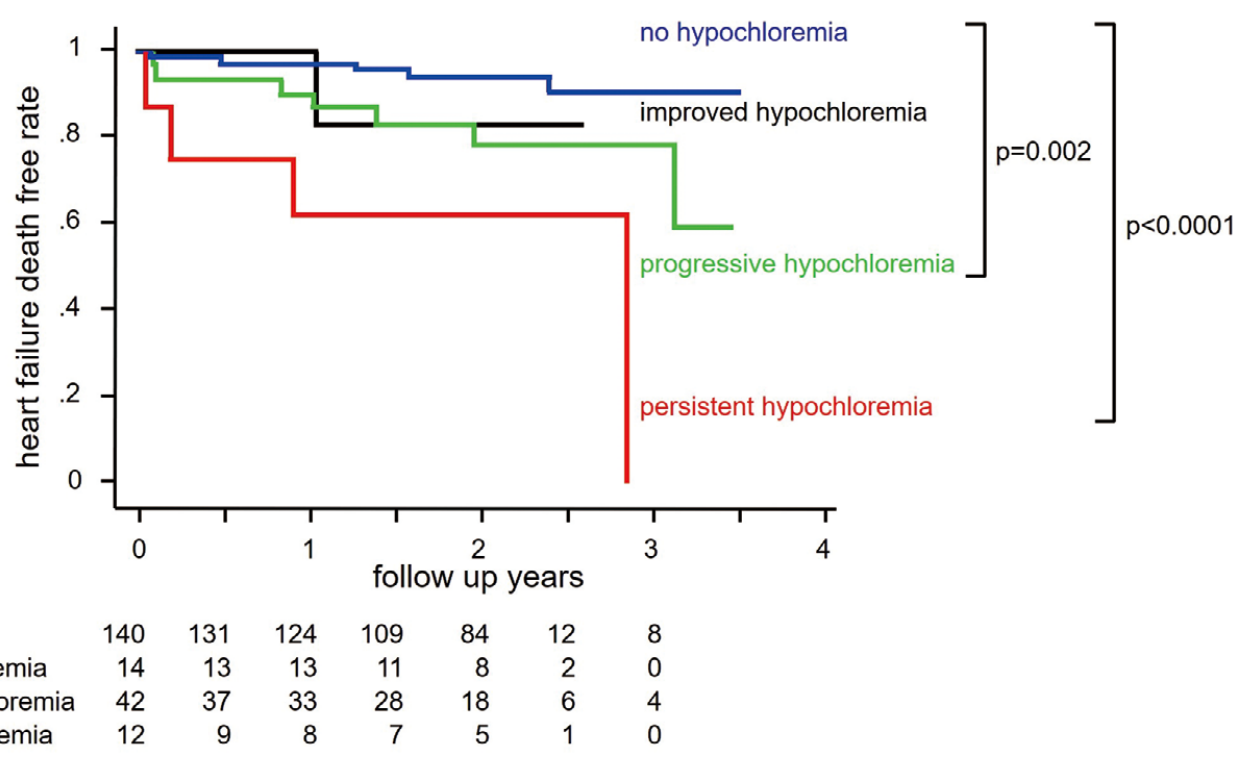

Figure 1. Heart failure death-free rate according to hypochloremia status on admission and at discharge in acute decompensated heart failure patients.

Number at risk

no hypochloremia improved hypochloremia progressive hypochloremia persistent hypochloremia

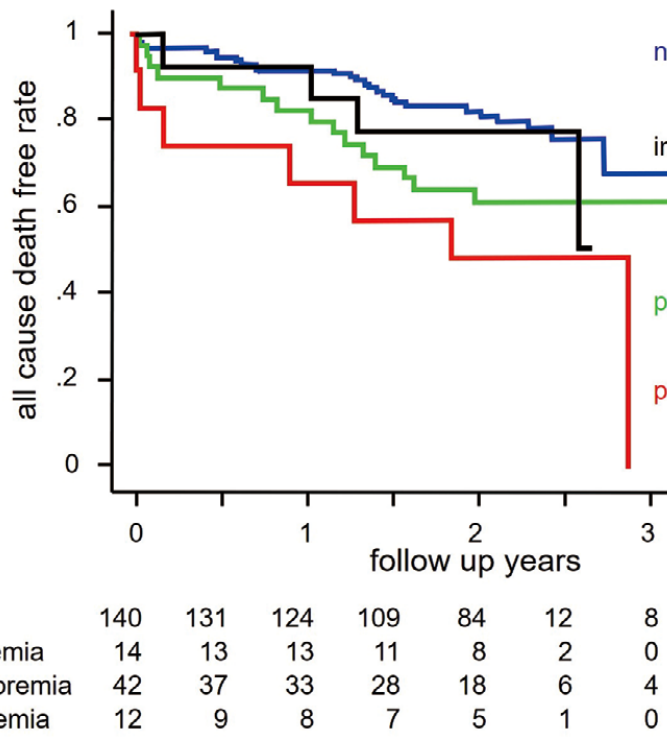

Figure 2. All-cause death-free rate according to hypochloremia status on admission and at discharge in acute decompensated heart failure patients.

$0.540-0.678)$.

HFD was observed in 4 of 12 patients (20.98 per 100 person-years) in the persistent hypochloremia group; in 8 of 42 (10.99 per 100 person-years) in the progressive hypochloremia group; in 2 of 14 (7.43 per 100 person-years) in the improved hypochloremia group; and in 6 of 140 (2.23 per 100 person-years) in the no hypochloremia group. Both patients with persistent hypochloremia $(\mathrm{P}<0.0001$;
HR, 9.13; 95\% CI: 2.56-32.55) and those with progressive hypochloremia $(\mathrm{P}=0.002$; HR, 4.65; 95\% CI: 1.61-13.4) had a significantly greater risk of HFD than those without hypochloremia during hospitalization (Figure 1). In contrast, there was no difference in non-cardiovascular death between these groups (persistent hypochloremia group, $1 / 12$ patients, $8 \%$; progressive hypochloremia group, 6/42 patients, $14 \%$; improved hypochloremia group, $2 / 14$ patients, 


\begin{tabular}{|c|c|c|c|c|}
\hline & \multicolumn{2}{|c|}{ Univariate analysis } & \multicolumn{2}{|c|}{ Multivariate analysis } \\
\hline & P-value & OR $(95 \% \mathrm{Cl})$ & P-value & OR $(95 \% \mathrm{Cl})$ \\
\hline Prior hospitalization & 0.006 & $2.520(1.300-4.900)$ & - & - \\
\hline Atrial fibrillation & 0.013 & $2.260(1.190-4.310)$ & 0.044 & $2.180(1.020-4.650)$ \\
\hline SBP & $<0.001$ & $0.983(0.973-0.993)$ & - & - \\
\hline \multicolumn{5}{|c|}{ Medications at discharge } \\
\hline ACEI or ARB & 0.004 & $0.386(0.203-0.732)$ & - & - \\
\hline Spironolactone & 0.048 & $1.880(1.010-3.530)$ & - & - \\
\hline Diuretics & 0.047 & $3.020(1.010-9.030)$ & - & - \\
\hline Diuretics dose & $<0.001$ & $1.030(1.010-1.050)$ & 0.047 & $1.020(1.000-1.040)$ \\
\hline \multicolumn{5}{|c|}{ Laboratory at discharge } \\
\hline Sodium & $<0.001$ & $0.727(0.651-0.813)$ & $<0.001$ & $0.736(0.657-0.825)$ \\
\hline Creatinine & 0.620 & $1.040(0.896-1.200)$ & & \\
\hline eGFR & 0.542 & $0.996(0.985-1.010)$ & & \\
\hline BUN & 0.003 & $1.030(1.010-1.040)$ & - & - \\
\hline
\end{tabular}

Abbreviations as in Table 1.

14\%; and no hypochloremia group, $13 / 140$ patients, $9 \%$ ). Regarding all-cause death, both patients with persistent hypochloremia ( $\mathrm{P}=0.001$, HR, 3.63; 95\% CI: $1.58-8.32)$ and those with progressive hypochloremia $(\mathrm{P}=0.016, \mathrm{HR}$, $2.10 ; 95 \% \mathrm{CI}: 1.14-3.90)$ had a significantly greater risk of all-cause death than those without hypochloremia during hospitalization (Figure 2).

On multivariate logistic regression analysis, AF, loop diuretics dose at discharge and serum sodium were independently associated with hypochloremia at discharge (Table 4).

\section{Discussion}

This study has shown that hypochloremia not only on admission but also at discharge is a predictor of HFD in ADHF patients. Hyponatremia, however, had no prognostic value in predicting HFD after adjustment for hypochloremia. Almost a quarter of ADHF patients had newly developed hypochloremia during hospitalization. Importantly, hypochloremia that progressed after admission was associated with a several-fold increased risk of HFD, as was persistent hypochloremia.

Chloride is responsible for modulation of renin secretion and tubular glomerular feedback. ${ }^{\mathbf{1 1 , 2 0}}$ Recent studies have identified a family of specific serine-threonine kinases called With-No-Lysine (WNK). WNK plays an essential role in regulating the actions of the RAAS and the transporters on which loop and thiazide diuretics work. ${ }^{12,13,21}$ Chloride seems to bind directly to the active site of WNK and inhibit WNK autophosphorylation, which decreases the availability of the sodium-potassium-chloride cotransporter and sodium-chloride cotransporter. ${ }^{12,21}$ Sensing of hypochloride by WNK causes upregulation of the sodiumpotassium-chloride cotransporter, exacerbates renal salt reabsorption and then attenuates the effect of loop diuretics. Thus, patients with hypochloremia might have activated RAAS and then difficulty in treatment with diuretics.

The prognostic power of hypochloremia to predict HFD was superior to that of hyponatremia in the present study. Both serum chloride and sodium could be lowered by several mechanisms. Patients with HF have exacerbated RAAS and a pleotropic effect of excess angiotensin II on renal salt and water reabsorption, resulting in abnormal renal loss of sodium and chloride, which might be modified by anti-HF therapy with diuretics. Many ADHF patients have limitation of salt intake as part of ADHF therapy. They therefore have water gain because of the decreased sodium chloride intake, and also decreased excretion of free water due to increased non-osmotic and baroreceptor-mediated arginine vasopressin release. ${ }^{1722}$ Serum chloride and sodium, however, could be lowered asymmetrically in HF patients. ${ }^{23}$ In the present study, 57 (44\%) of 130 patients with a decrease in serum chloride showed no simultaneous decrease in serum sodium, and $16(38 \%)$ of 42 patients with progressive hypochloremia did not have decrease in serum sodium during hospitalization, suggesting that change in serum chloride is independent of change in serum sodium. Radulović et al reported that increased in-hospital mortality was observed in ADHF patients with hypochloremia/ normonatremia but not in those with normochloremia/ hyponatremia. ${ }^{24}$ Mechanisms that specifically decrease serum chloride might be more important. Chloride is a buffer for cations, including acid and sodium, and plays an important role in the function of the kidney to excrete salt and water, therefore chloride has a broader homeostatic role than sodium. Thus, chloride might have superior prognostic value to sodium in ADHF.

In the present study, serial change in serum chloride also had great significance in the prognosis of ADHF. Patients with progressive hypochloremia as well as those with persistent hypochloremia had a significantly greater risk of HFD than those without hypochloremia. ADHF patients with progressive hypochloremia required a higher dose of loop diuretics than those without hypochloremia, and the dose of loop diuretics was significantly associated with hypochloremia at discharge on multivariate logistic regression analysis. Loop diuretic use at discharge is related to adverse outcome in ADHF patients. ${ }^{25}$ Hypochloremia at discharge might reflect the chronic use of higher loop diuretic dose, which could be responsible for poor clinical prognosis in ADHF patients. Thus, electrolyte imbalance after treatment could have prognostic significance in ADHF patients.

Serial change in serum chloride could be influenced by salt intake and diuretics. Given that we provided dietary 
counselling including salt restriction ( $\leq 6 \mathrm{~g} / \mathrm{day})$ for all ADHF patients during hospitalization, there was no difference in salt intake between the 4 groups according to hypochloremia on admission and at discharge. Therefore, in the present study, serum chloride level was not influenced by salt intake. In contrast, it is of clinical relevance to avoid the development of hypochloremia during hospitalization, because the present study has shown that newly developed hypochloremia during hospitalization is a risk factor for HFD in ADHF patients. In the present study, the loop diuretics dose and the prevalence of thiazides use during hospitalization were significantly greater in patients with progressive hypochloremia than in those without hypochloremia. This suggests that we might avoid progressive hypochloremia by adjusting loop diuretics dose or replacing thiazides with other diuretics such as tolvaptan, which does not induce RAAS activation. ${ }^{26-28}$

Serum chloride could be lowered as a result of anti-HF therapy such as diuretics, and hypochloremia might play a role as a severity marker of HF in ADHF patients. ${ }^{19,29}$ Several parameters in this study, such as low blood pressure, serum BUN, sodium and chloride on admission, were associated with hypochloremia at discharge on logistic regression analysis, and were associated with poor prognosis in ADHF patients.

\section{Study Limitations}

There are some limitations to our study. First, the small and empirically chosen sample size was a major limitation; the follow-up period was short; and the number of ADHF patients who had HFD was so small that we were unable to accurately assess the risk for HFD, especially in patients with persistent hypochloremia and improved hypochloremia. Second, this was an observational study and it remains uncertain whether treatment for hypochloremia, such as hypertonic saline, could also improve prognosis in ADHF. Thus, it remains uncertain whether hypochloremia could be a target of anti-HF treatment. The loop diuretics dose at discharge, however, was significantly associated with hypochloremia, and the adjustment of diuretic therapy to avoid hypochloremia and the resulting activation of the RAAS could provide better clinical outcome in ADHF patients. Third, the prevalence of ARB use at discharge was low, especially in patients with persistent and progressive hypochloremia. Hypochloremia might be associated with the activation of the RAAS, and the lower prevalence of RAAS inhibitor use might have caused the poor outcome in the hypochloremia group. Patients in the persistent hypochloremia group might have difficulty in taking ARB because of significantly poorer renal function or lower SBP. In the progressive hypochloremia group, ARB use was difficult or withdrawn because of severe renal dysfunction on admission $(\mathrm{n}=3)$ and hypotension $(\mathrm{n}=10)$, acute kidney injury $(\mathrm{n}=10)$, hyperkalemia $(\mathrm{n}=2)$ and acute ischemic stroke during hospitalization $(\mathrm{n}=2)$. These groups needed higher loop diuretic dose during hospitalization, which might result in the activated RAAS and the associated poor clinical outcome. Finally, in the present study, we did not assess serial change of serum chloride after discharge, therefore it is not known whether serum chloride after discharge might be lowered, in correlation with HFD in ADHF patients.

\section{Conclusions}

Both persistent hypochloremia and progressive hypochloremia were associated with a greater risk of HFD in ADHF patients. Hyponatremia was not significantly associated with HFD after adjustment for hypochloremia.

\section{Disclosures}

The authors declare no conflicts of interest.

\section{References}

1. Goldsmith SR, Francis GS, Cowley AW, Levine TB, Cohn JN Increased plasma arginine vasopressin levels in patients with congestive heart failure. J Am Coll Cardiol 1983; 1: 1385-1390.

2. Bavishi C, Ather S, Bambhroliya A, Jneid H, Virani SS, Bozkurt $\mathrm{B}$, et al. Prognostic significance of hyponatremia among ambulatory patients with heart failure and preserved and reduced ejection fractions. Am J Cardiol 2014; 113: 1834-1838.

3. Kusaka H, Sugiyama S, Yamamoto E, Akiyama E, Matsuzawa Y, Hirata Y, et al. Low-normal serum sodium and heart failurerelated events in patients with heart failure with preserved left ventricular ejection fraction. Circ J 2016; 80: 411-417.

4. Gheorghiade M, Abraham WT, Albert NM, Stough WG, Greenberg BH, O'Connor CM, et al. Relationship between admission serum sodium concentration and clinical outcomes in patients hospitalized for heart failure: An analysis from the OPTIMIZE-HF registry. Eur Heart J 2007; 28: 980-988.

5. Agrinier N, Thilly N, Briançon S, Juillière Y, Mertes PM, Villemot $\mathrm{JP}$, et al. Prognostic factors associated with 15-year mortality in patients with hospitalized systolic HF: Results of the observational community-based EPICAL cohort study. Int J Cardiol 2017; 228: 940-947.

6. Arao K, Fujiwara T, Sakakura K, Wada H, Sugawara Y, Suga $\mathrm{C}$, et al. Hyponatremia as a predictor for worsening heart failure in patients receiving cardiac resynchronization therapy. Circ J 2013; 77: $116-122$.

7. Grodin JL, Sun JL, Anstrom KJ, Chen HH, Starling RC, Testani $\mathrm{JM}$, et al. Implications of serum chloride homeostasis in acute heart failure (from ROSE-AHF). Am J Cardiol 2017; 119: 78-83.

8. Grodin JL, Simon J, Hachamovitch R, Wu Y, Jackson G, Halkar M, et al. Prognostic role of serum chloride levels in acute decompensated heart failure. J Am Coll Cardiol 2015; 66: 659666.

9. Grodin JL, Verbrugge FH, Ellis SG, Mullens W, Testani JM, Tang WH. Importance of abnormal chloride homeostasis in stable chronic heart failure. Circ Heart Fail 2016; 9: e002453.

10. Ter Maaten JM, Damman K, Hanberg JS, Givertz MM, Metra M, O'Connor CM, et al. Hypochloremia, diuretic resistance, and outcome in patients with acute heart failure. Circ Heart Fail 2016; 9: e003109.

11. Kotchen TA, Luke RG, Ott CE, Galla JH, Whitescarver S. Effect of chloride on renin and blood pressure responses to sodium chloride. Ann Intern Med 1983; 98: 817-822.

12. Piala AT, Moon TM, Akella R, He H, Cobb MH, Goldsmith EJ Chloride sensing by WNK1 kinase involves inhibition of autophosphorylation. Sci Signal 2014; 7: ra41.

13. Ponce-Coria J, San-Cristobal P, Kahle KT, Vazquez N, Pacheco-Alvarez D, de Los Heros P, et al. Regulation of NKCC2 by a chloride-sensing mechanism involving the WNK3 and SPAK kinases. Proc Natl Acad Sci USA 2008; 105: 8458-8463.

14. McKee PA, Castelli WP, McNamara PM, Kannel WB. The natural history of congestive heart failure: The Framingham study. N Engl J Med 1971; 285: 1441-1446.

15. World Medical Association. World Medical Association Declaration of Helsinki. JAMA 2013; 310: 2191.

16. Valente MAE, Voors AA, Damman K, Veldhuisen DJ Van, Massie BM, O'Connor CM, et al. Diuretic response in acute heart failure: Clinical characteristics and prognostic significance. Eur Heart J 2014; 35: 1284-1293.

17. Matsuo S, Imai E, Horio M, Yasuda Y, Tomita K, Nitta K, et al. Collaborators developing the Japanese equation for estimated GFR: Revised equations for estimated GFR from serum creatinine in Japan. Am J Kidney Dis 2009; 53: 982-992.

18. Adrogué HJ, Madias NE. Hyponatremia. N Engl J Med 2000; 342: $1581-1589$.

19. Kanda Y. Investigation of the freely available easy-to-use software "EZR" for medical statistics. Bone Marrow Transplant 2013; 
48: $452-458$.

20. Berend K, van Hulsteijn LH, Gans RO. Chloride: The queen of electrolytes? Eur J Intern Med 2012; 23: 203-211.

21. Subramanya A, Yang CL, McCormick J, Ellison D. WNK kinases regulate sodium chloride and potassium transport by the aldosterone-sensitive distal nephron. Kidney Int 2006; 70: 630 634.

22. Sica DA. Sodium and water retention in heart failure and diuretic therapy: Basic mechanisms. Cleve Clin J Med 2006; 73(Suppl 2): S2-S7.

23. Friedberg CK. Electrolyte and fluid disturbances in congestive heart failure. $N$ Engl J Med 1951; 245: 812-821.

24. Radulović $B$, Potočnjak I, Dokoza Terešak S, Trbušić M, Vrkić $\mathrm{N}$, Malogorski D, et al. Hypochloraemia as a predictor of developing hyponatraemia and poor outcome in acute heart failure patients. Int J Cardiol 2016; 212: 237-241.

25. Hamaguchi S, Kinugawa S, Tsuchihashi-Makaya M, Goto D, Yamada S, Yokoshiki H, et al. Loop diuretic use at discharge is associated with adverse outcomes in hospitalized patients with heart failure: A report from the Japanese Cardiac Registry of Heart Failure in Cardiology (JCARE-CARD). Circ J 2012; 76: $1920-1927$.

26. Onogawa T, Sakamoto Y, Nakamura S, Nakayama S, Fujiki $\mathrm{H}$, Yamamura $\mathrm{Y}$. Effects of tolvaptan on systemic and renal hemodynamic function in dogs with congestive heart failure. Cardiovasc Drugs Ther 2011; 25: s67-s76.

27. Dohi K, Ito M. Novel diuretic strategies for the treatment of heart failure in Japan. Circ J 2014; 78: 1816-1823.

28. Tamaki S, Sato Y, Yamada T, Morita T, Furukawa Y, Iwasaki $\mathrm{Y}$, et al. Tolvaptan reduces the risk of worsening renal function in patients with acute decompensated heart failure and preserved left ventricular ejection fraction. Circ J 2017; 81: 740-747.

29. Yancy CW, Jessup M, Bozkurt B, Butler J, Casey DE, Drazner $\mathrm{MH}$, et al. $2013 \mathrm{ACCF} / \mathrm{AHA}$ guideline for the management of heart failure: A report of the American College of Cardiology Foundation/American Heart Association Task Force on Practice Guidelines. J Am Coll Cardiol 2013; 62: e147-e239. 